\title{
Do neighborhood demographics, crime rates, and alcohol outlet density predict incidence, severity, and outcome of hospitalization for traumatic injury? A cross-sectional study of Dallas County, Texas, 2010
}

Alan Cook ${ }^{* *}$, Jennifer Reingle Gonzalez ${ }^{2}$ and Bijal A Balasubramanian²

\begin{abstract}
Background: Unintentional injury leads all other causes of death for those 1 to 45 years old. The expense of medical care for injured people is estimated to exceed $\$ 406$ billion annually. Given this burden on the population, the Centers for Disease Control and Prevention consistently refers to injury prevention as a national priority. We postulated that exposure to crime and the density of alcohol outlets in one's neighborhood will be positively associated with the incidence of hospitalization for and mortality from traumatic injuries, independent of other neighborhood characteristics.
\end{abstract}

Methods: We conducted a cross-sectional study with ecological and individual analyses. Patient-level data for traumatic injury, injury severity, and hospital mortality due to traumatic injury in 2010 were gathered from the Dallas-Fort Worth Hospital Council Foundation. Each case of traumatic injury or death was geospatially linked with neighborhood of origin information from the 2010 U.S. Census within Dallas County, Texas. This information was subsequently linked with crime data gathered from 20 local police departments and the Texas Alcoholic Beverage Commission alcohol outlet dataset. The crime data are the Part One crimes reported to the Federal Bureau of Investigation.

Results: The proportion of persons 65 years old or older was the strongest predictor of the incidence of hospitalization for traumatic injury ( $b=12.64,95 \%$ confidence interval $(\mathrm{Cl}) 8.73$ to 16.55$)$. In turn, the incidence of traumatic injury most strongly predicted the severity of traumatic injury $(b=0.008,95 \% \mathrm{Cl} 0.0003-0.0012)$. The tract-level unemployment rate was associated with a $5 \%$ increase in the odds of hospital mortality among hospitalized trauma patients.

Conclusions: Several neighborhood characteristics were associated with the incidence, severity, and hospital mortality from traumatic injury. However, crime rates and alcohol outlet density carried no such association. Prevention efforts should focus on neighborhood characteristics such as population density, mean age of the residents, and unemployment rate, regardless of crime rates and alcohol outlet density.

Keywords: Socioeconomic status; Crime; Trauma; Injury; Mortality; Alcohol outlets

\footnotetext{
* Correspondence: adcookmd@gmail.com

${ }^{1}$ Chandler Regional Medical Center, 485 South Dobson Road, Suite 201,

Chandler, AZ 85224, USA

Full list of author information is available at the end of the article
} 


\section{Background}

Traumatic injuries cost more than $\$ 406$ billion in medical care and lost productivity annually (Finkelstein et al. 2006), and unintentional injury remains the leading cause of death among several age groups in the USA (Centers for Disease Control and Prevention 2010). Thus, injury prevention is a national priority. Across numerous medical disciplines, socioeconomic status (SES) by various measures has been strongly associated with higher incidence rates, and severity of disease including cancers and cardiovascular diseases (Kucharska-Newton et al. 2011; Schwartz et al. 2003), greater operative mortality (Bennett et al. 2010), and poorer overall survival rates represented disproportionately in lower SES populations (Daly et al. 2002). Previous research suggest that neighborhood characteristics, including measures of SES, may reflect the relative availability and access to resources necessary for well-being which can in turn influence outcomes of medical care, particularly, in light of the limited access to healthcare in low-income communities (Braveman et al. 1988).

Because SES is a multidimensional construct (that continues to generate definitional debate), it is particularly important that multiple measurement sources be investigated to elucidate the effect of 'SES' along with other neighborhood characteristics on trauma incidence, injury severity, and hospital mortality. Previously identified predictors include the following: individual income, employment status, and education level (individual level) and household income, mean or median education level, and proportion of a population living below a given poverty level (neighborhood level) (Galobardes et al. 2006a, b; Daly et al. 2002). Prior studies characterizing traumatic injury within social contexts often focus on singular facets of a complex mosaic of economic and social neighborhood attributes (Newgard et al. 2011); however, each study has its own respective limitations. Specifically, the exclusion of one or more important confounding measures may distort the relationship between SES and the phenomena of traumatic injury (Cubbin et al. 2000; Hefernan et al. 2011; Marcin et al. 2003; Newgard et al. 2011; Zarzur et al. 2010; Rosen et al. 2009). As such, other factors shown to be associated with the occurrence and outcomes of traumatic injury must be taken into account.

Alcohol retail outlet density is one such factor. The associations between alcohol retail outlet density and pedestrian injury collisions, car crashes and related injuries, and assaults, including intimate partner violence have all been well described (LaScala et al. 2001; Treno et al. 2007; Holder et al. 2000; Scribner et al. 1995). Alcohol retail outlet density has been found to be associated with various neighborhood characteristics, including poverty and racial demographics (Berke et al. 2010). Each additional alcohol outlet has been shown to increase crime reports to police by $3 \%$. Moreover, alcohol has long been linked to the commission of crimes (Shupe 1953; Ladouceur and Temple 1985). Finally, both interpersonal and property crimes are associated with the incidence of trauma (Hashima and Finkelhor 1999; Zimring and Zuehl 1986; Wilkinson et al. 2008; Cook 1986).

Clearly, a deeper understanding of the complex interactions between environmental contexts, individual behavior, exposure to crime, and traumatic injury may inform and improve injury prevention initiatives. We conducted an epidemiologic investigation that comprehensively examined the relationship between multidimensional indicators of SES with a focus on crime rates and alcohol retail density in the neighborhood as risk factors for the incidence and severity of, and mortality from, traumatic injury, in Dallas County, Texas. This study is particularly unique in that contextual measures were geographically linked from larger data sources (e.g., the U.S. Census) via geocoding of trauma patient home addresses. We postulated that exposure to crime and the density of alcohol outlets in one's neighborhood will be positively associated with the incidence of hospitalization for and mortality from traumatic injuries, independent of established SES measures such as income, employment status, and education. Therefore, we sought to answer two specific research questions. First, are the crime rate and alcohol retail density in a patients' census tract positively associated with their odds of hospitalization for traumatic injury? Second, do crime rates and alcohol retail density positively predict higher levels of injury severity and mortality, independent of other neighborhood contextual measures, patient behavior, and demographic measures? These two research questions are systematically evaluated in this study.

\section{Methods}

Data sources

Contextual U.S. Census, crime, and alcohol outlet data

SES data were obtained from the 2010 United States Census website (U. S. Census Bureau 2012). These data included population estimates for each census tract included in this study, age and sex distributions, education levels, proportions of persons living below the federal poverty level, median household income, employment rates, housing information (such as rates of owneroccupied housing), and race/ethnicity information. Crime, alcohol retail establishment, and patients' hospitalization data were restricted to the year 2010 to be consistent with the United States Census data.

Data for major crimes were obtained via the Uniform Crime Reports (UCR) Part One crimes (Federal Bureau of Investigation 2004) which include homicide, forcible rape, robbery, assault, burglary (breaking and entering), larceny/theft (including theft from motor vehicles), unauthorized use of motor vehicles (theft of the motor 
vehicle), and arson. Crime data for 2010, including the type of crime and the address where the crime occurred was provided by 20 of the 26 cities in Dallas County. Patients from the six cities that did not provide data to the UCR were excluded from the study. Finally, the Texas Alcoholic Beverage Commission provided the addresses of alcoholic beverage retail establishments throughout the area of interest in this study. This allowed us to compute a 'density' of alcohol outlets given the estimated population size of each patient's 'neighborhood' census tract (alcohol retail outlets per census tract/estimated population size per census tract $\times 100,000=$ alcohol retail outlets per 100,000 population for a given census tract) (Berke et al. 2010). We included only those alcohol retailers with active licenses during 2010.

Patients were included in this study if they lived within 1 of the 20 police jurisdictions in Dallas County, Texas that provided crime data to the Federal Bureau of Investigation's Uniform Crime Reports (UCR) (Figure 1). The patients' initial hospitalization for traumatic injuries occurred during 2010. Any subsequent hospital admission for any individual patient was excluded from the dataset. Patients were excluded if they were 14 years old or younger or hospitalized for burns as the primary diagnosis, as these groups have their own injury and mortality prediction models.

\section{Patients: individual-level data}

Patient-level data were collected directly from the DallasFort Worth Hospital Council Foundation (DFWHCF), an organization that stores data from more than $90 \%$ of all hospital discharges across the North Texas region. After receiving institutional review board approval, we obtained patient-level data for each discharge, including self-reported patient demographics, home address, type of insurance, length of stay, International Classification of Diseases, Ninth Edition - Clinical Modification (ICD-9) codes for diagnoses, procedures, and external causes of injury and poisoning (E-codes). Comorbid conditions were enumerated using the Elixhauser Comorbidity Score (Elixhauser et al. 1998).

\section{Outcomes: trauma-related morbidity and mortality}

The severity of traumatic injury was measured as the probability of mortality using the Trauma Mortality Prediction Model for the ICD-9 lexicon (Glance et al. 2009). Hospital discharge status identified each patient as either alive or deceased.

\section{Statistical analysis \\ Geocoding and data linkage}

The addresses of patients hospitalized for traumatic injury were linked to crime rates and alcohol retail densities in their respective census tracts using ArcGIS version 10.1
(ESRI, Redlands, CA, USA) and the user-written Geocode routine for Stata 12 (StataCorp., College Station, TX, USA). The geocoding process was a point-in-polygon method using TIGER/Line shapefiles provided online by the U. S. Census Bureau (2012). All crime rates and alcohol retail densities were population-adjusted/100,000 persons per census tract.

Multi-level predictors of injury severity and hospital mortality were assessed using hierarchical regression methods in Stata 12 (StataCorp., College Station, TX, USA). Predictor variables were excluded from multivariate analysis if they were not related to the outcome in any bivariate analyses, unless they were theoretically related to our research questions (e.g., represented crime rates or alcohol outlet density), or were identified as particularly relevant predictors of traumatic injury in the literature reviewed above.

\section{Multi-level regression analyses}

Patient-level hospital mortality was analyzed using a hierarchical logit model (Moore et al. 2010) which corrected for random effects at both the hospital and census tract levels. Model discrimination was reported as area under the receiver operator characteristic (ROC) curve (Hosmer Jr et al. 2013). The variation in trauma/ 100,000 population among census tracts was analyzed as standardized incidence ratios (SIR), and for clarity, these results are presented as tables and geographically below (Figures 2 and 3). Sensitivity analyses were conducted to ensure that the six jurisdictions excluded from this study (because crime data were not available) did not differ from those included in the analysis on any relevant outcome or predictor variable.

\section{Results}

According to the 2010 U.S. Census, the population of Dallas County was estimated to be $2,348,702$ people, residing within 526 census tracts and occupying 908 square miles. The geographic boundary of this study encompassed 510 contiguous census tracts covering $89 \%$ of the total land area in Dallas County. Due to missing crime data by jurisdiction, the total population denominator for this study was 2,279,737, which represented $97.1 \%$ of the county population. Using data from the DFWHCF, 6,032 trauma patients met our selection criteria for inclusion. The descriptive characteristics of the sample, census tracts, and all independent and dependent variables at the individual and census tract levels are detailed in Table 1. There were 17,550 injuries, representing 1,040 separate ICD-9 codes, diagnosed in our cohort of 6,032 patients. A breakdown of these ICD-9 codes is provided in Tables 2, 3 , and 4 .

First, we expected that crime rates and alcohol outlet density, independent of SES, patient behavior, and demo- 


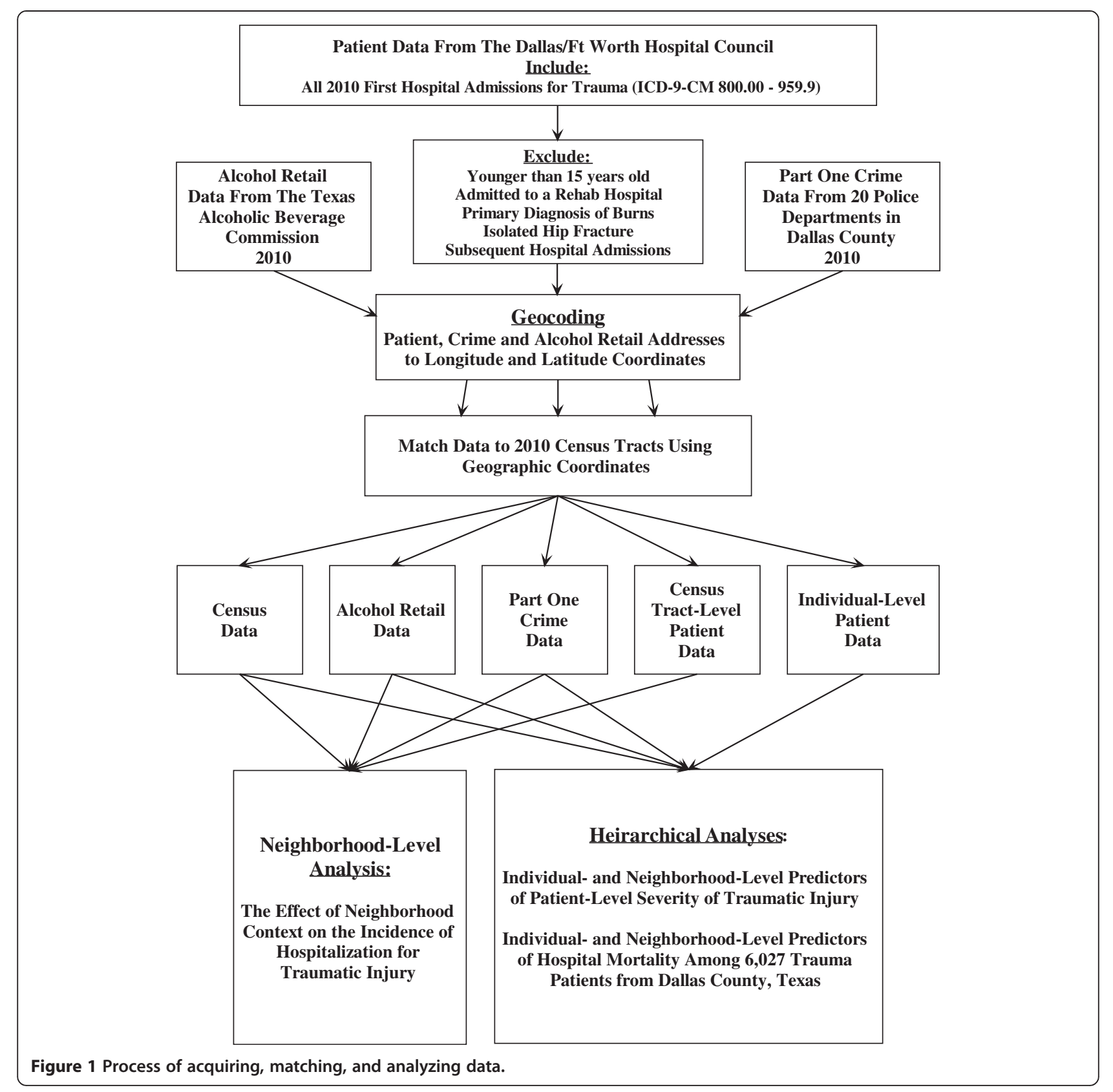

graphics, would be associated with the incidence of traumatic injuries sufficient to warrant hospitalization. The mean incidence of hospitalization for trauma was 264.05/100,000 (95\% confidence interval (CI) 260/100,000 to $273.83 / 100,000)$. Low proportions of owner-occupied housing, followed by the proportion of residents aged 65 years and older, were closely associated with traumatic injury (Table 5). Further, a greater proportion of tract residents younger than 18 was associated with a lower incidence of traumatic injury. A greater proportion of whites and blacks (compared to 'other races' and Hispanics/Latinos) living in the neighborhood was also associated with increased trauma rates, as the proportion of white and black residents was positively associated with traumatic injury. Population density (persons per square mile) was modestly protective from trauma, and neither the crime rate nor alcohol outlet densities were significant predictors of the incidence of hospitalization for treatment of traumatic injuries (Table 5).

Next, we examined whether neighborhood characteristics, beyond traditional SES measures, would predict the severity of traumatic injury and hospital mortality as a result of traumatic injury (in particular, the crime rate and density of alcohol retail outlets). We found that neither the rate of Part One crimes nor the density of alcohol retail outlets were associated with greater injury severity 


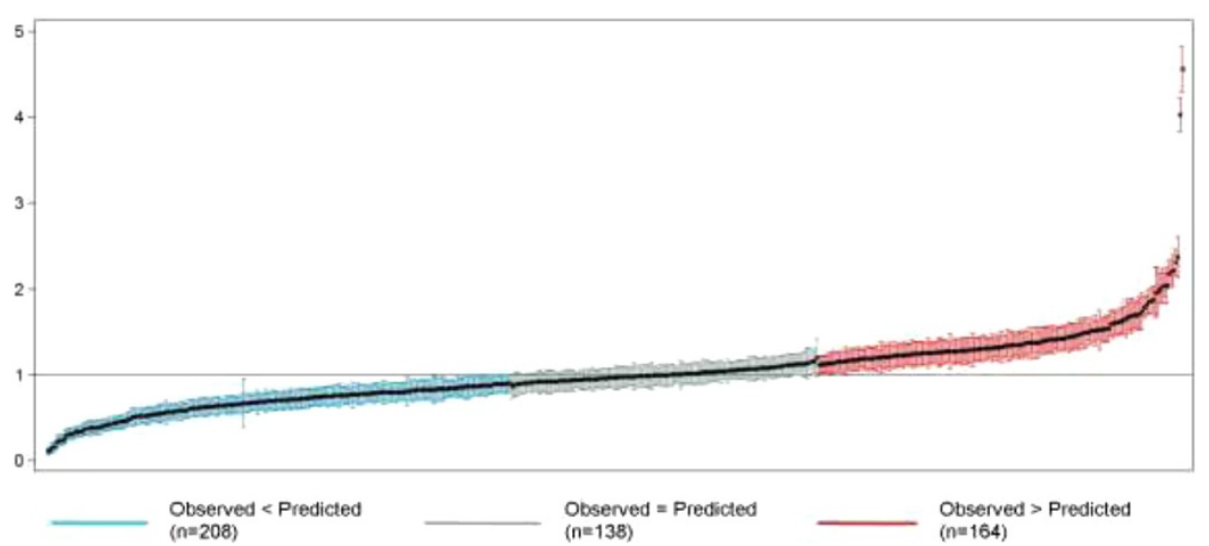

Figure 2 Standardized incidence ratios for traumas per 100,000 populations in 510 census tracts, Dallas County.

(Table 6). Individual characteristics, specifically, the number of medical comorbidities (Elixhauser Comorbidity Score), alcohol intoxication at hospital presentation, penetrating injury, and male sex were all positively associated with the severity of the traumatic injury. Black race, however, was associated with less severe injury than other races.

With respect to mortality from traumatic injuries, the unemployment rate was the only contextual SES predictor associated with mortality due to traumatic injury. Neither the crime rate nor the alcohol outlet density of the neighborhood was associated with traumatic mortality among citizens of Dallas County (Table 7). At the patient level, penetrating mechanism of injury was associated with two times the odds of mortality compared to other mechanisms of injury. Finally, more severe injuries were associated with greater mortality, and age was associated with a $4 \%$ increase in mortality due to trauma.

\section{Discussion}

We found that several well-established neighborhoodlevel SES measures were significantly associated with injury that required hospital admission and treatment. However, as expected, these predictors were less robust than individual-level characteristics of the patient. Further, the indicators of alcohol outlet density and crime rate in the neighborhood were not predictors in the present analysis. In summary, we found that other neighborhoodlevel SES predictors of traumatic injury included a lower population density, lower proportion of owner-occupied housing (e.g., more rental properties in a given neighborhood), the proportion of the tract population 18 years old or younger, as well as the percentage 65 years and older. Interestingly, both the neighborhood proportions of whites and black/African Americans exhibited a modest but significant increase in the incidence of hospitalization to treat traumatic injuries.

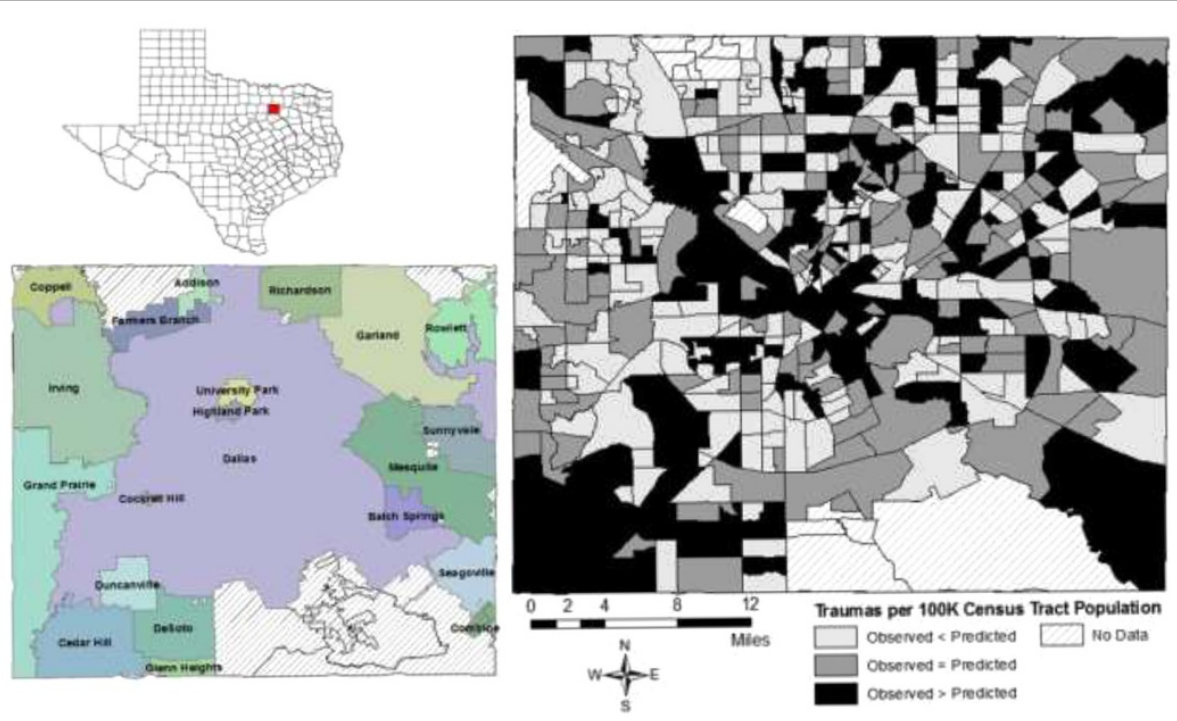

Figure 3 Standardized incidence rates of traumas per 100,000 census tract population, Dallas County. 
Table 1 Descriptive profile of individual and multi-level measures included in this analysis

\begin{tabular}{|c|c|c|}
\hline & $n(\%)$ & $\begin{array}{l}\text { Mean }(95 \% \mathrm{Cl}) \text { or } \\
\text { median (range)+ }\end{array}$ \\
\hline \multicolumn{3}{|l|}{ Outcomes } \\
\hline Mortality (discharged as 'dead') & $151(3.5)$ & \\
\hline $\begin{array}{l}\text { Hospitalizations for traumatic } \\
\text { injury/100,000 }\end{array}$ & - & $\begin{array}{l}\text { Median, } 263.46 \text {; range, } \\
21.15 \text { to } 1,560.14\end{array}$ \\
\hline Trauma patients/census tract & - & $\begin{array}{l}\text { Median, } 11 \text {; range, } \\
1 \text { to } 58\end{array}$ \\
\hline $\begin{array}{l}\text { Trauma Mortality } \\
\text { Prediction Model p(death) }\end{array}$ & - & $\begin{array}{l}\text { Median, } 1.57 \% \text {; range, } \\
0.001 \% \text { to } 94.01 \%\end{array}$ \\
\hline \multicolumn{3}{|l|}{ Independent variables: contextual } \\
\hline \multicolumn{3}{|l|}{$\begin{array}{l}\text { Census measures: } \\
\text { socioeconomic indicators }\end{array}$} \\
\hline \% Owner-occupied housing & - & 54.3 (52.0 to 56.7$)$ \\
\hline $\begin{array}{l}\% \text { of Population less than } \\
18 \text { years old }\end{array}$ & - & 26.4 (25.7 to 27.2$)$ \\
\hline $\begin{array}{l}\% \text { Estimated living below } \\
\text { poverty level }\end{array}$ & - & 18.7 (17.6 to 19.9$)$ \\
\hline $\begin{array}{l}\text { \% Unemployed } \\
\text { (previous } 12 \text { months) }\end{array}$ & - & 7.7 (7.3 to 8.1$)$ \\
\hline$\%$ High school graduates & - & 75.8 (74.3 to 77.4$)$ \\
\hline Median annual household (\$) & - & $\begin{array}{l}\text { Median, } \$ 46,188 \text {; range, } \\
\$ 11,875 \text { to } \$ 247,292\end{array}$ \\
\hline $\begin{array}{l}\text { Alcohol outlets/100,000 } \\
\text { population }\end{array}$ & - & 49.8 (41.9 to 57.7$)$ \\
\hline $\begin{array}{l}\text { Dallas county UCR crime } \\
\text { rate/100,000 population }\end{array}$ & & $8,823(7,753$ to 9,893$)$ \\
\hline $\begin{array}{l}\text { Independent variables: } \\
\text { demographic }\end{array}$ & & - \\
\hline $\begin{array}{l}\text { Population density } \\
\text { (population/square mile) }\end{array}$ & - & $\begin{array}{l}5,304.7(4,937.5 \\
\text { to } 5,671.8)\end{array}$ \\
\hline$\%$ White race & - & 58.4 (56.3 to 60.4) \\
\hline \% Black race & - & 21.2 (19.2 to 23.3$)$ \\
\hline \% Hispanic/Latino & - & 36.0 (33.7 to 38.2$)$ \\
\hline$\%$ Other races/multiracial & & $5.00(4.5$ to 5.6$)$ \\
\hline$\% 65$ and older & - & 9.4 (8.8 to 9.9$)$ \\
\hline \multicolumn{3}{|l|}{$\begin{array}{l}\text { Independent variables: } \\
\text { individual level }\end{array}$} \\
\hline \multicolumn{3}{|l|}{ Demographic } \\
\hline Sex (male) & $2,497(56.8)$ & \\
\hline Age (years) & - & $52.9(52.2$ to 53.6$)$ \\
\hline \multicolumn{3}{|l|}{ Race/ethnicity } \\
\hline White & $2,167(49.3)$ & - \\
\hline Hispanic/Latino & $1,118(25.4)$ & - \\
\hline Black & $889(20.2)$ & - \\
\hline Other races/multiracial & $221(5.0)$ & - \\
\hline \multicolumn{3}{|l|}{$\begin{array}{l}\text { Mechanism of injury/ } \\
\text { hospital records }\end{array}$} \\
\hline Blunt & $2,599(59.4)$ & - \\
\hline Penetrating & $288(6.6)$ & - \\
\hline
\end{tabular}

Table 1 Descriptive profile of individual and multi-level measures included in this analysis (Continued)

$\begin{array}{lcl}\text { Other/unknown } & 1,608(34.3) & - \\ \text { Elixhauser Comorbidity } & - & \text { Median, 2; range, } \\ \text { Score } & & 0 \text { to } 12 \\ \text { Alcohol intoxication } & 450(10.2) & - \\ \text { at hospital } & - & 5.8(5.5 \text { to } 6.0) \\ \begin{array}{l}\text { Length of hospital } \\ \text { stay (days) }\end{array} & \\ \text { means are presented unless otherwise specified. } & \end{array}$

The relationship between traumatic injury and neighborhood characteristics has been studied from various perspectives. Zarzur et al. found that neighborhood SES was inversely related to incidence rates of trauma; however, SES was defined only in terms of neighborhood income cut points in one county in Tennessee (Zarzur et al. 2010). Cubbin and colleagues noted that SES (in this case, income-to-need ratio, education level, occupation, race, ethnicity) is a robust predictor of mortality due to traumatic injury; however, the effect depended upon the indicator of SES and the cause and severity of injury (Cubbin and Smith 2002). Such factors include risktaking behavior, comorbid conditions, alcohol intoxication, and mechanism of injury. Since these phenomena appear to be multifactorial in nature, they should be investigated in a similar fashion. As we sought to understand how each measure of SES is independently associated with trauma morbidity and mortality, multiple levels of data (e.g., both neighborhood and individual level measures of income and poverty) were applied.

Injury prevention is a matter of increasing significance, as the Institute of Medicine published the report, 'HospitalBased Emergency Care: At the Breaking Point' due to the increasing demands of emergency and trauma care and the current capacity limitations in 2007 (Committee on the Future of Emergency Care in the United States Health System 2007). The authors state that, 'In 2003, nearly 114 million visits were made to hospital emergency departments... About one-quarter of those visits were due to unintentional injuries.' In 2011, the American Association for the Surgery of Trauma Prevention Committee issued a call to action for trauma centers, which recommended that prevention programs target neighborhoods where important socioeconomic and cultural factors need to be identified (Davis et al. 2011).

Although the relationship between race and traumatic injury has been well documented, there is limited research that incorporates both individual race of the patient and the racial composition of their home neighborhood. For instance, at the individual level, Cubbin et al. (2000) found that black adults were at $61 \%$ age-adjusted greater risk for 
Table 2 Types and frequencies of 17,550 injuries in 6,032 patients hospitalized for traumatic injuries in Dallas County, 2010

\begin{tabular}{|c|c|c|}
\hline Injuries & Number & Percent \\
\hline Femur, knee, tibia-fibula, ankle, foot fractures & 3,224 & 18.37 \\
\hline Arm, elbow, wrist, or hand fracture/dislocations & 1,526 & 8.70 \\
\hline Brain injuries $+/-$ coma & 1,455 & 8.29 \\
\hline Open wound injuries & 1,227 & 6.99 \\
\hline Eye, ear, face soft tissue, mouth, teeth injuries & 1,066 & 6.07 \\
\hline Facial fractures & 893 & 5.09 \\
\hline III-defined or non-specific injury ICD-9 code & 875 & 4.99 \\
\hline Thorax, heart, lungs, or diaphragm injuries & 846 & 4.82 \\
\hline Pelvic fractures & 839 & 4.78 \\
\hline Rib or sternum fractures & 701 & 3.99 \\
\hline Skull fracture $+/-$ brain injuries & 554 & 3.16 \\
\hline Contusion injuries & 513 & 2.92 \\
\hline $\begin{array}{l}\text { Lumbar spine fracture/dislocation }+/- \text { spinal } \\
\text { cord injuries }\end{array}$ & 504 & 2.87 \\
\hline $\begin{array}{l}\text { Cervical spine fracture/dislocation }+/- \text { spinal } \\
\text { cord injuries }\end{array}$ & 454 & 2.59 \\
\hline Pancreas, liver, spleen, adrenal gland injuries & 395 & 2.25 \\
\hline $\begin{array}{l}\text { Thoracic spine fracture/dislocation }+/- \text { spinal } \\
\text { cord injuries }\end{array}$ & 350 & 1.99 \\
\hline Sprains & 343 & 1.95 \\
\hline $\begin{array}{l}\text { Esophagus, stomach, small intestine, colon, rectum } \\
\text { injuries }\end{array}$ & 274 & 1.56 \\
\hline Vascular injuries & 244 & 1.39 \\
\hline Clavicle or scapula fractures & 230 & 1.31 \\
\hline Joint dislocations & 217 & 1.24 \\
\hline Spinal cord or nerve injuries & 191 & 1.09 \\
\hline Sacral/coccyx spine fracture/dislocations & 163 & 0.93 \\
\hline Kidneys, ureter, bladder, urethra injuries & 141 & 0.80 \\
\hline Injuries from foreign bodies & 88 & 0.50 \\
\hline Amputation injuries & 76 & 0.43 \\
\hline Crush injuries & 59 & 0.34 \\
\hline Genitalia, reproductive organ injuries & 47 & 0.27 \\
\hline Burn injuries & 34 & 0.19 \\
\hline Larynx, trachea, or thyroid injuries & 21 & 0.12 \\
\hline Total & 17,550 & 100.00 \\
\hline
\end{tabular}

traumatic injury compared to whites using the National Health Interview Survey data. Newgard and colleagues conducted an ecological study of emergency medical system (EMS) data from nine cities across the USA and Canada. This study reported a positive association between the rate of major traumatic injuries and the percentage of the non-white population (Newgard et al. 2011). Our results were concordant with the literature on race and
Table 3 OLS regression model predicting hospitalization for traumatic injury: The effect of neighborhood context

\begin{tabular}{lccc}
\hline & $\boldsymbol{b}$ & $\mathbf{9 5 \%} \mathrm{Cl}$ & $\boldsymbol{p}$ value \\
\hline $\begin{array}{l}\text { Contextual measures } \\
\begin{array}{l}\text { Alcohol outlets/100,000 } \\
\text { population }\end{array}\end{array}$ & 0.06 & -0.15 to 0.25 & 0.60 \\
$\begin{array}{l}\text { UCR crime rate/100,000 } \\
\begin{array}{l}\text { Population density } \\
\text { (population/square mile) }\end{array}\end{array}$ & -0.0002 & -0.001 to 0.0006 & 0.60 \\
$\begin{array}{l}\text { \% White race } \\
\text { \% Black race }\end{array}$ & 1.57 & -0.008 to -0.001 & 0.006 \\
\% Hispanic/Latino & 1.77 & 0.92 to 2.61 & $<0.001$ \\
\% 65 and older & -0.84 & -1.87 to 0.19 & 0.11 \\
\% Younger than 18 years old & -3.73 & -6.59 to -0.88 & 0.01 \\
\% Owner-occupied housing & -75.0 & -133.9 to -16.1 & 0.013 \\
\% High school graduates & -2.44 & -3.57 to -1.31 & $<0.001$ \\
Constant & 505.17 & 267.88 to 742.45 & $<0.001$ \\
\hline
\end{tabular}

traumatic injury, as we found a positive relationship between racial composition at the neighborhood level (e.g., proportion of black and white), and traumatic injury in general. However, we did find that blacks and whites (compared with Hispanic/Latinos and other racial groups) were more likely to have injuries of greater severity. These studies were substantively different from the present investigation, as each study evaluated one level of data only, and Cubbin and colleagues assessed mortality only, with risk factors assessed only at the individual level.

The role of ethnicity at the individual and neighborhood level provides an interesting albeit complex and multidimensional research question as it relates to traumatic injury and neighborhood context. Hispanics have rates of violence and crime that are closely approaching and surpassing those of blacks, and they are likely to live in areas that are characterized by social disorder, poor living conditions, and poverty (Gonzalez-Barrera and Lopez 2013; Reingle et al. 2012). Therefore, given the potential for traumatic injury due to violence and crime-related activity, we were surprised that Hispanic ethnicity was not identified as a risk factor for injury, injury severity, or mortality. We can only postulate that this may be a function of a lower likelihood of treatment seeking or measurement error (for instance, those of 'Hispanic/Latino' descent may be less likely to self-report this as a personal identity). However, elucidating the phenomena underlying this finding is beyond the scope of this study.

Our results regarding alcohol outlet density and trauma differ from the extant literature, and we expect that methodological differences may explain much of this variability. For instance, Mair et al. investigated the association 
Table 4 Hierarchical OLS regression model of individualand neighborhood-level predictors of injury severity

\begin{tabular}{lccc}
\hline & $\boldsymbol{b}$ & $\mathbf{9 5 \%} \mathrm{Cl}$ & $\boldsymbol{p}$ value \\
\hline $\begin{array}{l}\text { Contextual measures } \\
\begin{array}{l}\text { Crime rate/100,000 } \\
\text { population }\end{array}\end{array}$ & $2.6 \times 10^{-6}$ & $\begin{array}{c}-3.9 \times 10^{-6} \\
\text { to } 9.0 \times 10^{-6}\end{array}$ & 0.44 \\
$\begin{array}{l}\text { Alcohol outlet density } \\
\begin{array}{l}\text { Traumas/100,000 population } \\
\text { Patient-level measures }\end{array}\end{array}$ & 0.0008 & 0.0003 to 0.0012 & 0.002 \\
$\begin{array}{l}\text { Elixhauser Comorbidity } \\
\text { Score }\end{array}$ & 0.08 & 0.04 to 0.11 & $<0.001$ \\
$\begin{array}{l}\text { Alcohol intoxication } \\
\text { at hospital }\end{array}$ & 0.42 & 0.21 to 0.63 & $<0.001$ \\
$\begin{array}{l}\text { Penetrating mechanism } \\
\text { of injury }\end{array}$ & 0.38 & 0.09 to 0.67 & 0.01 \\
$\begin{array}{l}\text { Sex (male) } \\
\text { White race }\end{array}$ & 0.37 & 0.23 to 0.49 & $<0.001$ \\
$\begin{array}{l}\text { Black race } \\
\text { Hispanic/Latino ethnicity }\end{array}$ & -0.28 & -0.56 to 0.004 & 0.05 \\
Constant & -0.37 & -0.68 to -0.07 & 0.02 \\
\hline
\end{tabular}

between alcohol retail density, specifically bars, and assaultrelated injury hospitalizations. Mair observed a positive relationship between the number of alcohol outlets and injury due to assault; however, this effect varied according to the demographic characteristics of the neighborhood (Mair et al. 2012). In addition, studies of alcohol policy have found that reducing alcohol availability by reducing the number of alcohol outlets in a community or the hours and days of sale resulted in lower rates of injury almost immediately (Zhu et al. 2004; Scribner et al. 1999; Britt et al. 2005; Popova et al. 2009). Therefore, we expect

Table 5 Hierarchical logistic regression analysis predicting mortality among 6,027 trauma patients from Dallas County, Texas

\begin{tabular}{|c|c|c|c|}
\hline & OR & $95 \% \mathrm{Cl}$ & $p$ value \\
\hline \multicolumn{4}{|l|}{ Contextual measures } \\
\hline Part One crimes/100,000 & 1.00 & 1.00 to 1.00 & 0.42 \\
\hline Alcohol outlet density & 1.00 & 1.00 to 1.00 & 0.13 \\
\hline Unemployment rate & 1.05 & 1.00 to 1.09 & 0.02 \\
\hline \multicolumn{4}{|l|}{ Patient-level measures } \\
\hline Age & 1.04 & 1.01 to 1.09 & $<0.001$ \\
\hline Penetrating mechanism of injury & 1.98 & 1.12 to 3.40 & 0.02 \\
\hline Severity of injury ${ }^{a}$ & 2.94 & 2.55 to 3.40 & $<0.001$ \\
\hline Constant & 0.05 & 0.02 to 0.11 & $<0.001$ \\
\hline
\end{tabular}

This model estimates random effects at the hospital and census tract level. Area under the ROC curve $=0.89$, indicating a high sensitivity of the model alogit transformation of TMPM p(death). that this differential finding is a function of our inclusion of both on- and off-premise alcohol retail outlets as this distinction has been shown to have unique effects on outcome (Campbell et al. 2009). Further, alcohol retail outlets are more densely located in lower socioeconomic locations (Berke et al. 2010). Although not the primary focus of this paper, we believe that the intrinsic correlation between alcohol outlets and neighborhood SES will account for the lack of observed independent effect of alcohol outlets on traumatic injury.

Mortality from traumatic injury has long been the focus of research to identify risk and protective factors that are amendable to intervention in the hospital setting. Typically, this research models the risk of highly specific types of injuries, injury patterns, or the benefits of various treatments. However, researchers have recently begun to expand the scope of their research beyond the hospital walls to investigate how features of the geographic and social environment contribute to traumatic injury mortality (Alkhoury et al. 2009; Arthur et al. 2008; Centerwall 1995; Chapman et al. 2010; Cubbin et al. 2000; Haider et al. 2008). This inclusion of administrative, diagnostic, trauma registry data has tremendous potential to identify the cases of injury and mortality where self-reported information and arrest data do not suffice.

Our study has several limitations. First, we limited our geographic scope to include the census tracts with crime rate data (excluding six police jurisdictions that did not provide such data). While this allowed inclusion of $89 \%$ of the land area and $97.1 \%$ of the county population, limited selection bias was observed (see Tables 2, 3, and 4). Other limitations of this study include the administrative nature of the hospital discharge data. Although $64.2 \%$ of the patients in this study were treated at verified trauma centers, where registrars carefully document pertinent injury and clinical data, no clinical or administrative database is entirely free of error. Next, our analyses treat the patient as if all received comparable levels of exposure to the neighborhood characteristics (at the census tract level) examined, and the duration of each patient's exposure to their respective environments cannot be measured with these data. Moreover, all traumatic injuries were given equal weight with regard to association with the predictors though differences in association may exist among subgroups of injuries and predictors. Finally, all of the UCR index crimes were aggregated to define a tract's 'crime rate,' as we did not have a specific hypothesis as to which types of crime might be most closely related to traumatic injury.

In light of these limitations, the major strength of this paper is the broad, epidemiologic perspective it provides. 
Table $6 T$ test or $x^{2}$ comparison of patients included (versus those excluded) and census tracts in Dallas County

\begin{tabular}{|c|c|c|c|}
\hline & $\begin{array}{c}\text { Included } \\
N(\%) \text { or mean }(95 \% \mathrm{Cl})\end{array}$ & $\begin{array}{c}\text { Excluded } \\
N(\%) \text { or mean }(95 \% \mathrm{Cl})\end{array}$ & $p$ value \\
\hline Patient-level variables & $n=6,078$ & $n=161$ & \\
\hline \multicolumn{4}{|l|}{ Demographic information } \\
\hline Age & 54.6 (54.0 to 55.2$)$ & 57.1 (53.7 to 60.6) & 0.16 \\
\hline Sex (male) & $3,339(54.8)$ & $78(48.5)$ & 0.11 \\
\hline Race/ethnicity & & & 0.51 \\
\hline White & $3,099(51.0)$ & $89(55.3)$ & \\
\hline Black & $1,216(20.0)$ & $34(21.1)$ & \\
\hline Hispanic/Latino & $1,459(24.0)$ & $32(19.9)$ & \\
\hline All other races & $304(5.0)$ & $6(3.7)$ & \\
\hline \multicolumn{4}{|l|}{ Healthcare/event data } \\
\hline Uninsured & $1,618(26.6)$ & $25(15.5)$ & 0.002 \\
\hline Alcohol intoxication & $595(9.8)$ & $13(8.1)$ & 0.47 \\
\hline Elixhauser Comorbidity Score & $2.0(2.0$ to 2.1$)$ & 2.1 (1.9 to 2.4 ) & 0.50 \\
\hline Length of hospital stay (days) & $5.6(5.4$ to 5.8$)$ & 4.6 (3.8 to 5.4$)$ & 0.02 \\
\hline Trauma center admission & $3,920(64.5)$ & $95(59.0)$ & 0.15 \\
\hline Penetrating mechanism of injury & $546(10.8)$ & $8(5.8)$ & 0.06 \\
\hline TMPM, p(death) & 0.05 (0.05 to 0.05$)$ & 0.04 (0.03 to 0.07 ) & 0.14 \\
\hline Died & $191(3.2)$ & $3(1.9)$ & 0.35 \\
\hline Census tract-level variables & $n=510$ & $n=16$ & \\
\hline Trauma/100,000 & 344.8 (328.2 to 361.4$)$ & 275.5 (220.1 to 331.0) & 0.02 \\
\hline Alcohol retail/100,000 & $49.4(41.6$ to 57.2$)$ & 41.7 (18.9 to 64.5$)$ & 0.51 \\
\hline Population density & $5,311.7(4,944.2$ to 5679.2$)$ & $4,146.5(2,610.6$ to $5,682.5)$ & 0.14 \\
\hline$\%$ Younger than 18 & 26.4 (25.7 to 27.1$)$ & 27.9 (24.4 to 31.4$)$ & 0.38 \\
\hline$\% 65$ and older & 9.4 (8.8 to 9.9$)$ & $7.9(6.1$ to 9.7$)$ & 0.12 \\
\hline$\%$ White race & 58.5 (56.4 to 60.5$)$ & 62.7 (50.1 to 75.2$)$ & 0.49 \\
\hline$\%$ Black race & $21.2(19.1$ to 23.2$)$ & 23.5 (9.3 to 37.7$)$ & 0.74 \\
\hline \% Hispanic/Latino & 35.8 (33.5 to 38.0$)$ & 36.7 (22.9 to 50.5$)$ & 0.89 \\
\hline$\%$ High school graduates & 76.1 (74.5 to 77.7$)$ & $73.5(62.2$ to 84.7$)$ & 0.64 \\
\hline \% Owner-occupied housing & $54.3(51.9$ to 56.6$)$ & 60.7 (47.1 to 74.3$)$ & 0.34 \\
\hline Median household income in thousands & $\$ 55.9$ (52.9 to 58.9$)$ & $\$ 53.5$ (45.2 to 61.8$)$ & 0.58 \\
\hline Living below poverty level & $18.6(17.4$ to 19.7$)$ & 14.1 (9.3 to 21.0$)$ & 0.24 \\
\hline Unemployment, age 20 to 64 years old & 7.7 (7.3 to 8.1$)$ & $6.0(4.7$ to 7.2$)$ & 0.01 \\
\hline
\end{tabular}

Despite the large number of studies that have been done in this field, this study is one of the most comprehensive, investigatory, epidemiological studies to date to establish the correlates at both the neighborhood and individual level using hospital data, census information, police records, and alcoholic beverage licensing datasets. Further, we were able to establish direct associations between multi-level measures and 'injury' in general. This is important epidemiologically in terms of prevention; communities with high crime rates or diverse racial compositions may be identified as ideal locations for primary prevention.

\section{Conclusions}

Although individual-level measures were more robust predictors of traumatic injury and mortality, neighborhood-level crime and context plays a role in the incidence of traumatic injury requiring hospitalization. Further research is needed to assess which injury prevention efforts may yield the greatest benefit in reducing rates of traumatic injury and mortality, as even small effects at the neighborhood level may have vast effects on the targeted population as a whole. 
Table 7 Logistic regression assessing selection effects for census tracts included in this study

\begin{tabular}{lccc}
\hline & Odds ratio & $\mathbf{9 5 \%} \mathbf{C l}$ & $\boldsymbol{p}$ value \\
\hline $\begin{array}{l}\text { Census tract measures } \\
\text { Trauma/100,000 population }\end{array}$ & 1.00 & 1.00 to 1.01 & 0.04 \\
$\begin{array}{l}\text { Alcohol outlet density } \\
\text { Demographic measures }\end{array}$ & 1.00 & 1.00 to 1.01 & 0.66 \\
$\begin{array}{l}\text { \% White race } \\
\text { \% Black race }\end{array}$ & 0.92 & 0.86 to 0.99 & 0.02 \\
\% Other race & 0.92 & 0.86 to 0.98 & 0.01 \\
High school graduates & Ref & - & \\
$\begin{array}{l}\text { Below poverty level } \\
\text { (past 12 months) }\end{array}$ & 1.07 & 1.01 to 1.11 & 0.001 \\
Constant & 1.10 & 1.03 to 1.17 & 0.004 \\
\hline
\end{tabular}

\section{Abbreviations}

95\% Cl: 95\% confidence interval; DFWHCF: Dallas-Fort Worth Hospital Council Foundation; ICD-9: International Classification of Diseases, Ninth Edition - Clinical Modification; ROC: receiver operator characteristic; SES: socioeconomic status; UCR: Uniform Crime Report.

\section{Competing interests}

The authors declare that they have no competing interests.

\section{Authors' contributions}

AC made substantial contributions to the study design, acquisition of the data, computer modeling and statistical analysis, interpretation of the results, and manuscript development. JR made substantial contributions to the study design, statistical analysis, interpretation of the results, and critical revision of the manuscript. BB made substantial contributions to the study design, statistical analysis, and interpretation of the results. All authors read and approved the final manuscript.

\section{Acknowledgements}

The authors are grateful for the assistance of the following Dallas County police departments for supplying crime data for this study: Addison, Balch Springs, Cedar Hill, Coppell, Dallas, DeSoto, Duncanville, Farmers Branch, Garland, Glenn Heights, Grand Prairie, Highland Park, Irving, Mesquite, Richardson, Rowlett, Seagoville, and University Park.

\section{Author details}

${ }^{1}$ Chandler Regional Medical Center, 485 South Dobson Road, Suite 201, Chandler, AZ 85224, USA. ${ }^{2}$ University of Texas School of Public Health, Dallas Regional Campus, Dallas, Texas 75390, USA.

Received: 29 June 2014 Accepted: 16 August 2014

Published online: 20 October 2014

\section{References}

Alkhoury F, Yood S, Yood MU, Martin JT, Wells K, Helton S, Zuckerman R. Insurance status and geography but not race affect mortality in penetrating trauma victims. J Am Coll Surg. 2009; 209(3):S98.

Arthur M, Hedges JR, Newgard CD, Diggs BS, Mullins RJ. Racial disparities in mortality among adults hospitalized after injury. Med Care. 2008; 46(2):192-99. doi:10.1097/MLR.0b013e31815b9d8e.

Bennett KM, Scarborough JE, Pappas TN, Kepler TB. Patient socioeconomic status is an independent predictor of operative mortality. Ann Surg. 2010; 252(3):552-57. doi:10.1097/SLA.0b013e3181f2ac64. discussion 7-8.

Berke EM, Tanski SE, Demidenko E, Alford-Teaster J, Shi X, Sargent JD. Alcohol retail density and demographic predictors of health disparities: a geographic analysis. Am J Public Health. 2010; 100(10):1967-71. doi:10.2105/ AJPH.2009.170464.
Braveman P, Oliva G, Miller MG, Schaaf VM, Reiter R. Women without health insurance. Links between access, poverty, ethnicity, and health. West J Med. 1988; 149(6):708-11.

Britt HR, Carlin BP, Toomey TL, Wagenaar AC. Neighborhood level spatial analysis of the relationship between alcohol outlet density and criminal violence. Environ Ecol Stat. 2005; 12(4):411-26.

Campbell CA, Hahn RA, Elder R, Brewer R, Chattopadhyay S, Fielding J, Naimi TS, Toomey T, Lawrence B, Middleton, JC. The effectiveness of limiting alcoho outlet density as a means of reducing excessive alcohol consumption and alcohol-related harms. Am J Prev Med. 2009; 37(6):556-69.

Centers for Disease Control and Prevention. Web-based Injury Statistics Query and Reporting System (WISQARS) [online] (2010), Centers for Disease Control and Prevention. 2010. http://www.cdc.gov/injury/wisqars/. Accessed 21 July 2013.

Centerwall BS. Race, socioeconomic status, and domestic homicide. JAMA. 1995; 273(22):1755-58.

Chapman BP, Fiscella K, Kawachi I, Duberstein PR. Personality, socioeconomic status, and all-cause mortality in the United States. Am J Epidemiol. 2010; 171(1):83-92. doi:10.1093/aje/kwp323.

Committee on the Future of Emergency Care in the United States Health System. Hospital-Based Emergency Care: At the Breaking Point. Bethesda, Maryland: The National Academies Press; 2007.

Cook PJ. The relationship between victim resistance and injury in noncommercial robbery. J Legal Stud. 1986; 16:405-16.

Cubbin C, Smith GS. Socioeconomic inequalities in injury: critical issues in design and analysis. Ann Rev Public Health. 2002; 23:349-75.

Cubbin C, LeClere FB, Smith GS. Socioeconomic status and the occurrence of fatal and nonfatal injury in the United States. Am J Public Health. 2000; 90(1):70-7.

Daly MC, Duncan GJ, McDonough P, Williams DR. Optimal indicators of socioeconomic status for health research. Am J Public Health. 2002; 92(7):1151-57.

Davis JW, Sise MJ, Albrecht R, Kuhls DA. American Association for the Surgery of Trauma Prevention Committee topical updates: getting started, fall prevention, domestic violence, and suicide. J Trauma. 2011; 70(4):996-1001. doi10.1097/TA.0b013e318210894e.

Elixhauser A, Steiner C, Harris D, Coffey R. Comorbidity measures for use with administrative data. Med Care. 1998; 36(1):8-27.

Federal Bureau of Investigation. Uniform Crime Reporting Handbook. In: U.S. Department of Justice, editor. Clarksburg, WV: U.S. Department of Justice; 2004.

Finkelstein E, Corso PS, Miller TR. The Incidence and Economic Burden of Injuries in the United States. Oxford: Oxford University Press; 2006.

Galobardes B, Shaw M, Lawlor DA, Lynch JW, Davey Smith G. Indicators of socioeconomic position (part 1). J Epidemiol Community Health. 2006a; 60(1):7-12. doi:10.1136/jech.2004.023531.

Galobardes B, Shaw M, Lawlor DA, Lynch JW, Davey Smith G. Indicators of socioeconomic position (part 2). J Epidemiol Community Health. 2006b; 60(2):95-101. doi:10.1136/jech.2004.028092.

Glance LG, Osler TM, Mukamel DB, Meredith W, Wagner J, Dick AW. TMPM-ICD9: a trauma mortality prediction model based on ICD-9-CM codes. Ann Surg. 2009; 249(6):1032-39. doi:10.1097/SLA.0b013e3181a38f28.

Gonzalez-Barrera A, Lopez MH. A Demographic Portrait of Mexican-Origin Hispanics in the United States. Washington DC: Pew Research Hispanic Center Retrieved; 2013

Haider AH, Chang DC, Efron DT, Haut ER, Crandall M, Cornwell EE III. Race and insurance status as risk factors for trauma mortality. Arch Surg. 2008; 143(10):945.

Hashima PY, Finkelhor D. Violent victimization of youth versus adults in the National Crime Victimization Survey. J Interpers Violence. 1999; 14(8):799-820.

Hefernan DS, Vera RM, Monaghan SF, Thakkar RK, Kozloff MS, Connolly M, Gregg SS, Machan JT, Harrington DT, Charles A, Adams J, Cioffi WG. Impact of socioethnic factors on outcomes following traumatic brain injury. J Trauma. 2011; 70(3):527-34.

Holder HD, Gruenewald PJ, Ponicki WR, Treno AJ, Grube JW, Saltz RF, Voas RB, Reynolds R, Davis J, Sanchez L, Gaumont G, Roeper P. Effect of communitybased interventions on high-risk drinking and alcohol-related injuries. JAMA. 2000; 284(18):2341-47.

Hosmer DW Jr, Lemeshow S, Sturdivant RX. Assessing the Fit of the Model. Applied Logistic Regression. Hoboken: Wiley; 2013: p. 173-82.

Kucharska-Newton AM, Harald K, Rosamond WD, Rose KM, Rea TD, Salomaa V. Socioeconomic indicators and the risk of acute coronary heart disease 
events: comparison of population-based data from the United States and Finland. Ann Epidemiol. 2011; 21(8):572-79. doi:10.1016/j. annepidem.2011.04.006.

Ladouceur P, Temple M. Substance use among rapists: a comparison with other serious felons. Crime Delinquency. 1985; 31(2):269-94.

LaScala EA, Johnson FW, Gruenewald PJ. Neighborhood characteristics of alcohol-related pedestrian injury collisions: a geostatistical analysis. Prev Sci. 2001; 2(2):123-34

Mair C, Gruenewald PJ, Ponicki WR, Remer L. Varying impacts of alcohol outlet densities on violent assaults: explaining differences across neighborhoods. J Stud Alcohol Drugs. 2012; 74(1):50.

Marcin JP, Schembri MS, He J, Romano PS. A population-based analysis of socioeconomic status and insurance status and their relationship with pediatric trauma hospitalization and mortality rates. Am J Public Health 2003; 93(3):461-66. doi:10.2105/ajph.93.3.461.

Moore L, Hanley JA, Turgeon AF, Lavoie A. Evaluating the performance of trauma centers: hierarchical modeling should be used. J Trauma Acute Care Surg. 2010; 69(5):1132-37.

Newgard CD, Schmicker RH, Sopko G, Andrusiek D, Bialkowski W. Minei JP. Brasel K, Bulger E, Fleischman RJ, Kerby JD, Bigham BL, Warden CR. Trauma in the neighborhood: a geospatial analysis and assessment of social determinants of major injury in North America. Am J Public Health. 2011; 101(4):669-77. doi:10.2105/ajph.2010.300063.

Popova S, Giesbrecht N, Bekmuradov D, Patra J. Hours and days of sale and density of alcohol outlets: impacts on alcohol consumption and damage: a systematic review. Alcohol Alcohol. 2009; 44(5):500-16.

Reingle JM, Maldonado-Molina MM, Jennings WG, Komro KA. Racial/ethnic differences in trajectories of aggression in a longitudinal sample of high-risk, urban youth. J Adolesc Health. 2012; 51(1):45-52. doi:10.1016/j. jadohealth.2011.11.008.

Rosen H, Saleh F, Lipsitz SR, Meara JG, Rogers SO Jr. Lack of insurance negatively affects trauma mortality in US children. J Pediatr Surg. 2009; 44(10):1952-57. doi:10.1016/j.jpedsurg.2008.12.026.

Schwartz KL, Crossley-May H, Vigneau FD, Brown K, Banerjee M. Race, socioeconomic status and stage at diagnosis for five common malignancies. Cancer Causes Control. 2003; 14(8):761-66.

Scribner RA, Mackinnon DP, Dwyer JH. The risk of assaultive violence and alcohol availability in Los Angeles County. Am J Public Health. 1995; 85(3):335-40.

Scribner R, Cohen D, Kaplan S, Allen SH. Alcohol availability and homicide in New Orleans: conceptual considerations for small area analysis of the effect of alcohol outlet density. J Stud Alcohol Drugs. 1999; 60(3):310.

Shupe LM. Alcohol and crime: a study of the urine alcohol concentration found in 882 persons arrested during or immediately after the commission of a felony. J Crim L Criminol Police Sci. 1953; 44:661.

Treno AJ, Johnson FW, Remer LG, Gruenewald PJ. The impact of outlet densities on alcohol-related crashes: a spatial panel approach. Accid Anal Prev. 2007; 39(5):894-901. doi:10.1016/j.aap.2006.12.011.

U. S. Census Bureau. American FactFinder. 2012. http://factfinder2.census.gov/ faces/nav/jsf/pages/index.xhtml. Accessed 5 Dec 2012.

Wilkinson RG, Kawachi I, Kennedy BP. Mortality, the social environment, crime and violence. Sociol Health IIIn. 2008; 20(5):578-97.

Zarzur B, Croce M, Fabian T, Fischer P, Magnotti L. A population-based analysis of neighborhood socioeconomic status and injury admission rates and in-hospital mortality. J Am Coll Surg. 2010; 211(2):216-23.

Zhu L, Gorman DM, Horel S. Alcohol outlet density and violence: a geospatial analysis. Alcohol Alcohol. 2004; 39(4):369-75.

Zimring FE, Zuehl J. Victim injury and death in urban robbery: a Chicago study. J Legal Stud. 1986; 15:1.

doi:10.1186/s40621-014-0023-2

Cite this article as: Cook et al.: Do neighborhood demographics, crime rates, and alcohol outlet density predict incidence, severity, and outcome of hospitalization for traumatic injury? A cross-sectional study of Dallas County, Texas, 2010. Injury Epidemiology 2014 1:23.

\section{Submit your manuscript to a SpringerOpen ${ }^{\odot}$ journal and benefit from:}

- Convenient online submission

- Rigorous peer review

- Immediate publication on acceptance

- Open access: articles freely available online

- High visibility within the field

- Retaining the copyright to your article

Submit your next manuscript at $\gg$ springeropen.com 